\title{
The importance of achieving disease control in Acromegaly: a retrospective single center analysis
}

\section{Varadhan, B Jose, RN Clayton}

\section{Dept of Diabetes \& Endocrinology, Royal Stoke University Hospital, University Hospitals of North Midlands NHS trust, Stoke on Trent, UK}

\section{Introduction}

- Growth hormone (GH) excess in acromegaly is associated with higher mortality and morbidity

- With improved treatment for acromegaly, many studies have demonstrated latest mortality rates to be improving and comparable to the general population (Schofl 2012 Eur J Endocrinol; Varadhan 2016 Pituitary)

- Though the SMR for acromegaly per se is improving with time, The mortality rates remain high largely due to cancers and circulatory disease (Esposito 2018 Eur J Endocrinol)

- Acromegaly is associated with significant morbidity (Dekkers $2008 \mathrm{~J}$ Clin Endocrino Metab)

- There are not many studies that have looked at the predictors of morbidity associated with acromegaly

- Development of comorbidities such as cardiovascular events and cancers are an important cause of mortality (Varadhan 2016 Pituitary)

- A recent study used lgF1 as a marker but this may not be available in all patients who have been follow up for more than 2 decades (Jayasena 2011 Clin Endocrinol)

- The duration of diabetes preceding the diagnosis of acromegaly is unaccounted for and could contribute to morbidity of acromegaly (Vallette 2013 Clin Endocrinol)

-The frequency of pituitary surgery to aim for cure for this condition has been progressively increasing (Esposito 2018 Eur J Endocrinol)

- Patients with acromegaly continue to have significant comorbidities, especially cancers, cardiovascular diseases, diabetes and hypopituitarism, which can account for a significant financial burden on health care system (Lesen 2017 Eur J Endocrinol)

\section{Ain}

The aim of the study was to assess the differences in mortality and morbidity associated with active acromegaly compared to patients in whom disease control was achieved

\section{Methods}

- Single centre study : Retrospective clinical observational study

- Data on all patients with acromegaly who had been treated since 1948

-1948-2014 used for data collection

- All GH results were converted to $\mathrm{mcg} / \mathrm{L}$

- Divided into 'control-achieved' and 'active disease group' for calculations

- Data at baseline including proportion with macroadenomas, pituitary axes failures and cardiovascular events (diabetes, hypertension, strokes, MI and CCF) labelled as CVE, were collected

- Details regarding treatment modalities used: surgery, radiotherapy and medical treatment were counted and the number of times each was done was counted

- Medical treatment included Somatostatin analogues, cabergoline/ bromocriptine or Pegvisomant

- Each therapy was counted as a course if treatment sustained beyond 3 months continuously

- Patients with repeated course of same therapy were counted as independent episodes

- Control was deemed achieved if latest GH consistently $<1.5 \mathrm{mcg} / \mathrm{L}$

- Data on mortality and CVE and duration to the events were calculated

- IgF-1 was not included in this analysis due to lack of sufficient data

\section{Results}

- $\mathrm{N}=167$

- Control-achieved in 116 patients

\section{Results}

\begin{tabular}{|l|c|c|c|}
\hline $\begin{array}{c}\text { Control- } \\
\text { achieved }\end{array}$ & $\begin{array}{c}\text { Active } \\
\text { Disease }\end{array}$ & p \\
\hline $\mathrm{N}=$ & 116 & 51 & \\
\hline At diagnosis & $47.5 \pm 13.3$ & $53.9 \pm 12.9$ & $<0.005$ \\
\hline Age & $16.6 \pm 25.5$ & $28.6 \pm 36.3$ & $<0.05$ \\
\hline $\mathrm{GH}(\mathrm{mcg} / \mathrm{L})$ & $9.5 \%$ & $16 \%$ & $\mathrm{NS}$ \\
\hline Patients with pit. Axes failure & $78.5 \%$ & $82 \%$ & $<0.001$ \\
\hline Macroadenomas & & & \\
\hline At follow-up & $163 \pm 118$ & $102 \pm 110$ & $\mathrm{NS}$ \\
\hline Duration follow up (months) & $65.5 \%$ & $46.2 \%$ & $<0.0005$ \\
\hline Patients surgery done & $1.1(1-3)$ & $1.3(1-3)$ & $\mathrm{NS}$ \\
\hline Mean number of surgeries & $98.3 \%$ & $82.7 \%$ & $\mathrm{NS}$ \\
\hline among operated & $1(1-5)$ & $0.8(1-4)$ & $\mathrm{NS}$ \\
\hline Patients with medical Rx & 2.25 & 1.8 & $\mathrm{NS}$ \\
\hline Mean no. of medical courses & & & \\
\hline Total no. of treatment & $38.2 \%$ & $32 \%$ & $\mathrm{NS}$ \\
\hline modalities & $1.8(1-3)$ & $1.5(1-4)$ & $\mathrm{NS}$ \\
\hline New pituitary axes failure & $33.6 \%$ & $36 \%$ & $\mathrm{NS}$ \\
\hline No. of total new failed axes & $144 \pm 112$ & $69 \pm 110$ & $<0.05$ \\
\hline New CVE & $30.2 \%$ & $64 \%$ & $<0.0001$ \\
\hline Duration to CVE (months) & &
\end{tabular}

\section{Discussion}

- The initial GH at diagnosis and macroadenomas were significantly higher in the active disease group, suggesting more severe disease

- The proportion of patients operated was higher in the group were control achieved, again showing surgery as the most successful form of treatment

- The number of treatment modalities required to achieve control was higher compared to group where control not achieved, suggesting that a more aggressive approach may be helpful

- Though CVE was equal in both groups, the duration to achieve control was higher in patients where control achieved, again highlighting the benefit of curing acromegaly

- The mortality rates were higher in the active disease group

- Though the total number of treatment modalities was higher, the proportion suffering with further pituitary axes failure was comparable between the two groups

\section{- Limitations of our analysis}

- Retrospective analysis not allow for calculating incidence rates

- Regression analysis could not performed as data on various other confounding factors for mortality and morbidity were not available

- Data on cancer prevalence and cause of death was not available for this study

\section{Conclusion}

- Mortality rates from acromegaly were higher in patients with active disease

- Disease burden from acromegaly is significantly high in both 'controlachieved' as well as 'active disease' group; however the duration to develop these complications can be prolonged by achieving contro

- The various available treatment options would need to be explored, with surgery being the preferred choice, to aim to achieve biochemical contro of acromegaly to reduce the risk of complications 